\title{
Política de defensa del usuario de servicios financieros. Bases conceptuales
}

\author{
Adrián Zelaia Ulibarri ${ }^{1}$ \\ Presidente de Ekai Center, Innovating Public Policy
}

Recibido: $\quad 28.02 .11$

Aceptado: 29.03.11

Sumario: I. Necesidad de una política específica. II. Efectos de la crisis financiera. III. Falta de transparencia y protección del usuario. IV. La sorprendente inactividad política. V. Las medidas de gobierno corporativo no son un instrumento sustancial. VI. La regulación de instrumentos concretos no es suficiente. VII. Innovación financiera y globalización. VIII. Agencias de rating. IX. Mercado de derivados. X. La interconexión entre banca comercial y mercado de valores. XI. Regulación financiera y políticas anti-crisis. XII. Sobre el crédito-vivienda. XIII. Sobre la protección del ahorrador frente a la inflación. XIV. Las políticas reguladoras. XV. Algunas claves para la reforma. XVI. Un baño de realidad. XVII. Algunos comentarios finales.

Resumen: La crisis financiera ha puesto de relieve déficits esenciales en la protección del usuario de servicios financieros, tanto como depositante/inversor como en cuanto prestatario. Aunque la necesidad de proteger al consumidor de servicios financieros ha adquirido una relevancia dramática como consecuencia de la crisis financiera, la pasividad política de los 3 primeros años de crisis ha provocado un cierto escepticismo. Es urgente una reflexión de fondo sobre cómo actuar con la sobrefinanciación acumulada de las familias y las empresas de una forma lo menos traumática posible pero asegurando una reducción progresiva del riesgo «sistémico» de la misma.

Palabras clave: crisis financiera, servicios financieros, defensa del consumidor, sobrefinanciación.

Abstract: The financial crisis has highlighted critical gaps in the protection of financial services users, both as depositors/investors as well as lenders. While the need to protect financial services users has become vital as a result of the financial crisis, lack of political action during the first three years of the crisis has caused certain scepticism. In-depth reflection is urgently needed on

1 As a Working Paper, it doesn't reflect any institutional position or opinion of EKAI Center. 
how to proceed with the over financing accumulated by families and firms to ensure a progressive reduction of the "systemic» risk in the least drastic manner possible.

Key words: financial crisis, financial services, consumer protection, over financing. 


\section{Sobre las bases conceptuales de la política de defensa del consumidor de servicios financieros}

\section{Necesidad de una política específica}

1. La tradicional justificación de la necesidad de políticas específicas de protección del usuario de servicios financieros se ha asentado, sintéticamente, en los conceptos siguientes:

a) La necesidad de evitar que la protección jurídica de los derechos del usuario sea teórica más que real, como consecuencia del coste o la complejidad de las reclamaciones.

b) La necesidad de corregir imperfecciones habituales de la relación entre empresa y cliente: déficits de información o comprensión, posiciones de dominio de las empresas sobre los usuarios...

c) La necesidad de compensar imperfecciones estructurales del mercado financiero: dominio del mercado / regulación / protección pública.

2. El consumidor de servicios financieros tiene especiales problemas por razones estructurales del sector:

a) Progresiva complejidad y falta de transparencia.

b) Creciente lejanía entre el ahorrador y el receptor de la inversión.

c) Insuficiente «disciplina de mercado».

d) Falta de fiabilidad de la acción pública protectora del consumidor.

\section{Efectos de la crisis financiera}

3. La crisis financiera ha puesto de relieve déficits esenciales en la protección del usuario de servicios financieros, tanto como depositante/ inversor como en cuanto prestatario.

4. La crisis financiera ha llevado también a trastocar las prioridades de las políticas de protección del usuario. Ya no preocupan tanto figuras contractuales $u$ operaciones financieras concretas y los problemas a abordar se centran en los dos siguientes:

a) La necesidad de proteger a familias y empresas frente a la caída del crédito bancario.

b) La protección de los depositantes frente a riesgos de determinadas entidades bancarias o frente a una posible elevada inflación. 


\section{Falta de transparencia y protección del usuario}

5. La falta de transparencia en las operaciones financieras ha sido uno de los factores clave que contribuyeron a la crisis actual. Es cierto que, con frecuencia, se ha utilizado la complejidad de los contratos financieros como una excusa para justificar la falta de transparencia. Pero también lo es que, en ocasiones, esta complejidad ha sido voluntariamente diseñada precisamente con el objetivo de dificultar la correcta comprensión de las operaciones.

Las medidas de mejora de la transparencia en las operaciones financieras son esenciales para combatir el cortoplacismo, la excesiva asunción de riesgos y las conductas pro-cíclicas.

6. Los recientes posicionamientos de la Unión Europea se han mostrado favorables a combatir la falta de transparencia mediante un seguimiento y regulaciones exhaustivos, con el objetivo de que «ningún agente, ningún mercado o ningún producto» quede exento de una adecuada regulación y supervisión.

El objetivo pretendido por la U.E. es el de garantizar que se dispone de información apropiada y fiable no sólo sobre las características de los productos, sino también sobre el funcionamiento de los mercados financieros. Estrategias como el Marco Europeo de Supervisión, la regulación de las agencias de rating o el nuevo régimen de sanciones, pretenden asegurar que las autoridades reguladoras dispongan también de las herramientas adecuadas para garantizar la correcta supervisión del sector.

La mejora de la responsabilidad y de la protección del usuario se pretende conseguir a través de medidas contra el abuso de mercado, sanciones más estrictas y mejoras de gobierno corporativo.

\section{La sorprendente inactividad política}

7. La reforma de la Política de Defensa del Usuario de Servicios Financieros $-\mathrm{y}$, en conjunto, la reforma de la regulación financiera europea- llega excesivamente tarde. Han transcurrido ya tres años y medio desde el estallido de la crisis financiera en julio de 2007 y aún no se han adoptado medidas de fondo al respecto.

Esta inactividad, evidente en la generalidad de los Estados occidentales y en la Unión Europea, se detecta también en el ámbito del G-20, en el que parece que los distintos países han depositado sus esperanzas para la adopción de medidas de reforma que, transcurridos los años, no acaban de ponerse en marcha. 


\section{Las medidas de gobierno corporativo no son un instrumento sustancial}

8. Las estrategias y la Hoja de Ruta definidas en la Unión Europea para la reforma de la regulación de la defensa de los usuarios de servicios financieros confían excesivamente en las medidas de gobierno corporativo. Ninguna reforma del gobierno corporativo de las entidades financieras puede superar los problemas estructurales del sistema financiero, más relacionados con el insuficiente nivel de competencia interna, la configuración de los bancos centrales y el sistema bancario y monetario en su conjunto.

En concreto, el cortoplacismo y la excesiva asunción de riesgos no es en absoluto una consecuencia de prácticas de gobierno corporativo incorrectas, sino producto directo de un sistema que incentiva directamente la asunción excesiva de riesgos a corto plazo con el amparo de la expectativa razonable y constatada de acceso privilegiado a los recursos públicos cuando son necesarios para resolver los déficits generados.

\section{La regulación de instrumentos concretos no es suficiente}

9. La Unión Europea ya ha adoptado algunas medidas concretas de interés para la protección de los consumidores en operaciones como el crédito al consumo o la venta a distancia de servicios financieros.

10. No obstante, regulaciones puntuales y exhaustivas de operaciones e instrumentos financieros específicos difícilmente van a resolver a medio plazo los problemas derivados de los recursos financieros privilegiados aportados al sector bancario por los bancos centrales y el altísimo incentivo al riesgo que los mismos generan.

\section{Innovación financiera y globalización}

11. Es cierto que los desarrollos técnicos en conjunto denominados como «innovación financiera» han transformado la gestión de riesgos de las entidades financieras, los precios y el catálogo de productos. A la vez, la desintermediación financiera, la transferencia y securitización del riesgo de crédito, han distorsionado seriamente la percepción del riesgo de las entidades que en cada momento adoptan las decisiones de crédito.

12. Los pequeños ahorradores/inversores con frecuencia no tienen información correcta sobre el destinatario final o sobre los intermedia- 
rios en los que están invirtiendo. La información es fundamental para el correcto funcionamiento del mercado y para la defensa de los intereses de los usuarios.

13. Las ventajas teóricas de la globalización financiera parecían evidentes: maximizar la eficacia de la intermediación, extender a todo el mundo la posibilidad de conectar los entornos/países con ahorro y los que necesitan recursos para consumo o inversión y maximizar la conexión entre oferta y demanda de recursos financieros a nivel global.

Sin embargo, ahora parece evidente que la globalización financiera, más que una oportunidad, se ha convertido en un problema de fondo. Frente a las teóricas ventajas citadas, la globalización ha disparado los riesgos que para los usuarios se derivan de los defectos de información:

a) Cuanta mayor lejanía entre el depositante/inversor y el destinatario, menor es el conocimiento del destino final y mayores los riesgos.

b) El conocimiento sobre el destinatario final de las inversiones es insuficiente.

c) El conocimiento sobre el intermediario es insuficiente.

d) El poder en manos de las agencias de rating es excesivo. La lejanía obliga a depender de este tipo de intermediarios.

e) Con frecuencia, los recursos no provienen de los ahorradores, sino de donde se «crea» dinero artificialmente: Bancos Centrales, Wall Street/City...

f) El peso de los factores «de imagen» de la entidad intermediaria es excesivo.

De esta forma, ahora parece evidente que son mucho más importantes los problemas derivados de la globalización financiera que sus ventajas, como consecuencia de la pérdida de enraizamiento de las entidades financieras y de la pérdida de la perspectiva del riesgo derivada del alejamiento entre ahorrador y receptor final de los recursos.

Ni la regulación financiera ni la capacidad de gestión de las crisis financieras han avanzado de forma coherente con estos cambios del entorno financiero.

\section{Agencias de rating}

14. Es precisamente el alejamiento entre ahorrador y destinatario de los recursos financieros generado por la globalización lo que ha generado un desconocimiento de los riesgos reales y el consiguiente auge 
de las agencias de rating como referencia necesaria para los inversores, a falta de un conocimiento real directo.

La concentración e insuficiente nivel de competencia entre las agencias de rating, junto al poder político de las mismas, ha evidenciado la necesidad de una intervención pública directa en este sector. Es necesario al respecto:

- Cuestionarse los criterios de Basilea soportados en las valoraciones de las agencias de rating.

- Establecer incompatibilidades más estrictas.

- Crear agencias de rating públicas.

\section{Mercado de derivados}

15. Es sorprendente que durante estos años transcurridos de crisis, aún no se hayan adoptado medidas contundentes con respecto al mercado de derivados. Ni la prohibición que ya en 2007 propusieron numerosos expertos y responsables políticos, ni la prohibición parcial de los contratos sin contrapartida de un riesgo real, ni siquiera una estandarización o regulación de los contratos o la obligatoriedad de contratación en mercados organizados como se plantea ahora la Unión Europea.

Es evidente que la trascendencia de estas operaciones para la gran banca occidental hacía políticamente difícil emprender actuaciones contundentes en este mercado. Por otro lado, la importancia de sus efectos en las entidades financieras obligaba probablemente a enmarcar esta posible actuación en un paquete de medidas más amplio de reestructuración del sector financiero occidental, reestructuración que debería haberse abordado y que no ha tenido lugar.

\section{$X$. La interconexión entre banca comercial y mercado de valores}

16. Por su parte, la desregulación financiera de las últimas décadas ha tenido como consecuencia el fenómeno de la «interconexión» entre el marcado bancario y el mercado de capitales, que ha supuesto un daño evidente para la protección de los derechos de los depositantes de la banca comercial.

Como consecuencia de esta interconexión:

- Se ha incentivado que los bancos comerciales invirtieran en operaciones especulativas, poniendo en grave riesgo los intereses de los depositantes. 
- Los activos de alto riesgo se han estado beneficiando de la cobertura pública y los tipos de interés privilegiados en principio destinados a la actividad bancaria comercial.

- Los inversores en activos especulativos se han beneficiado «incluso de las políticas de rescate bancario», que sólo tienen sentido para proteger a la banca comercial.

Parece evidente la trascendencia que esta interconexión ha tenido en el origen de esta crisis financiera.

17. El sector bancario tiene una naturaleza específica como sector protegido y con niveles de competencia limitados. Los riesgos habituales del sector bancario para sus depositantes (y los resultados) se han multiplicado como consecuencia de la intervención sistemática de los bancos en los mercados especulativos.

Como ya hemos indicado, el gobierno corporativo y los sistemas remunerativos de los ejecutivos financieros no son el problema sino un mero síntoma. El problema esencial es probablemente el alto incentivo al riesgo derivado de un sistema de protección pública mal gestionado. Este riesgo se ha multiplicado al permitir a los bancos entrar masivamente en operaciones de alto riesgo en los mercados.

El carácter de «entidades bancarias» constituye en sí mismo para los directivos de los grandes bancos, como consecuencia de la protección pública y del acceso privilegiado a la influencia política, una conciencia de riesgo limitado de sus actividades.

Estos defectos estructurales del sistema bancario sólo pueden tener justificación en el contexto de la banca comercial, en el que se pretende asegurar la protección de los depositantes y del crédito productivo. Proteger con recursos públicos actividades especulativas en los mercados financieros carece de cualquier tipo de justificación social o económica y provoca un evidente incremento del riesgo para los depositantes.

Por todo ello, la desconexión entre mercado bancario y mercado de valores debería ser una prioridad de la política de regulación del sector financiero y en la protección de los usuarios en los países occidentales.

A la vez, sería necesario un activo posicionamiento político para actuar también sobre los efectos ya sufridos en el sector bancario como consecuencia de la interconexión y evitar al menos que el riesgo ya generado en la especulación en los mercados financieros:

a) Se beneficie de ayudas públicas que sólo corresponden a la actividad bancaria.

b) Arrastre a las entidades bancarias comerciales (depositantes y prestatarios).

c) Arrastre a la economía real, gobiernos, familias y empresas. 


\section{Regulación financiera y políticas anti-crisis}

18. Aunque en ocasiones parece darse a entender lo contrario, en principio, el objetivo «conceptual» de la actual oleada reguladora de los servicios financieros en la UE y en el G-20 no es la lucha contra la crisis.

El objetivo «conceptual» real de estas medidas, tal como han puesto de manifiesto repetidamente en los documentos de la Comisión Europea, no es otro que «evitar que lo que ha sucedido vuelva a suceder».

Ello acredita que todas estas medidas, aunque se hagan efectivas, no van a resolver la actual situación de sobrefinanciación acumulada en las familias, empresas y estados, la falta de crédito bancario o los riesgos de los depositantes y de los titulares de créditos-vivienda.

\section{Sobre el crédito-vivienda}

19. Ante la realidad de una crisis financiera que puede continuar y agravarse, los desahucios por impagos de créditos-vivienda pueden convertirse en un problema estructural y una tragedia colectiva en ciertos países occidentales, tanto desde el punto de vista humano como social y económico.

Si bien, desde un punto de vista teórico, cabría argumentar que una persona concreta debiera ser responsable de haber solicitado un crédito que no debía, esta argumentación pierde toda su base cuando es el conjunto de una sociedad el que se ha sometido a esta dinámica y cientos de miles o millones las familias con dificultades para hacer frente al reembolso de los créditos.

De cualquier forma, complementariamente, cabe preguntarse si una sociedad avanzada puede permitirse abandonar a su suerte a cientos de miles/millones de personas.

Si la crisis financiera continúa avanzando en la dirección que se teme, no habrá otro remedio que compartir responsabilidades a través de la reestructuración de la deuda. Fundamentalmente en lo que respecta a los créditos-vivienda, es imprescindible abordar con urgencia la preparación de la normativa necesaria al respecto.

No es sólo una cuestión de solidaridad, sino de supervivencia de nuestra estructura social y productiva.

\section{Sobre la protección del ahorrador frente a la inflación}

20. Desde el inicio de la crisis financiera, los Bancos Centrales ( $y$, sobre todo, la Reserva Federal USA) están disparando la oferta moneta- 
ria. Esto supone un riesgo evidente de elevada inflación a medio plazo, en el momento de reanimación del crédito bancario.

Otro hipotético riesgo sería que, tras una eventual ruptura de la Eurozona, los países con problemas de competitividad recurrieran inmediatamente a la devaluación.

La inflación es una forma de redistribución de recursos más injusta, y social y económicamente más perjudicial, pero con menor coste político que la subida de impuestos o la reducción de gastos sociales.

La protección del ahorrador frente a la pérdida de valor del dinero sólo puede provenir de un sistema monetario con mayores garantías de estabilidad que el actual o bien de una adecuada gestión política, manifestada en:

a) Una gestión prudente y rigurosa de los bancos centrales

b) Sensibilidad política y social frente a los efectos «injustos» de las devaluaciones.

\section{Las políticas reguladoras}

21. También en las políticas de defensa del usuario de servicios financieros, un posicionamiento excesivamente simplista ha llevado a generar una dialéctica política centrada en la opción entre «mayor o menor» regulación.

Sin embargo, como hemos puesto repetidamente de manifiesto en EKAl Center, el sector financiero es probablemente el más regulado. No sólo se regula la actividad financiera, la información, el destino de los resultados, ... Incluso el precio de las «compras» de dinero es determinado por el Estado (bancos centrales)

La cuestión clave no es, por lo tanto, mayor o menor regulación, sino asegurar que las decisiones regulatorias (tanto el qué se regula o no como el cómo se regula) se adoptan en base al interés general y no en base a intereses particulares.

Con excesiva frecuencia, una regulación aparentemente «limitativa» y defensora de los derechos de los usuarios tiene como efecto restringir la competencia e incluso «beneficiar» a las entidades reguladas.

\section{$\mathrm{XV}$. Algunas claves para la reforma}

22. La nueva Política de Defensa del Consumidor de Servicios Financieros debe apostar por el reconocimiento y fomento de las enti- 
dades financieras «pegadas al terreno». La globalización financiera no está funcionando.

Es imprescindible atacar de forma inmediata y decidida la «interconexión» entre los mercados bancario y de valores.

Sólo el depósito y el crédito deberían ser beneficiarios de protección pública. Banca comercial y banca de inversión deberían estar perfectamente diferenciadas tanto a efectos de la utilización del recurso a los bancos centrales como a efectos de las políticas de rescate.

Debe replantearse el sistema de tipos de interés de la banca central, limitando su financiación privilegiada al crédito social y al crédito productivo.

Deben regularse de forma sustancialmente más estricta las agencias de rating y los instrumentos financieros derivados

La salida de la crisis financiera exige dar prioridad a reanimar el crédito productivo y a garantizar los depósitos bancarios. Para ello es imprescindible una política de estricto ajuste de la actividad bancaria con finalización del sistema de interconexión.

Finalmente, es evidente que el deterioro de la estructura y del funcionamiento del sector financiero se debe en buena parte a los defectos en la gestión política derivados de la excesiva influencia política de determinadas entidades del sector financiero. La resolución de los problemas de fondo del sistema financiero exige abordar los déficits estructurales de la gestión política de una buena parte de los estados occidentales.

\section{$\mathrm{XVI}$. Un baño de realidad}

23. A pesar de la gravedad y urgencia de las actuaciones a realizar, la realidad de la acción política en relación con este tema es la siguiente:

— G-20 «ha decidido» que en 2011 «analizará» vías «para avanzar» en la protección de los consumidores en el mercado financiero.

— La UE ha aprobado una «Hoja de Ruta».

- Basel III «incrementará» los requisitos de capital de los bancos.

Como conclusión, aunque sea difícil de creer, la realidad es que, tras tres años y medio de crisis financiera... aún no se han adoptado decisiones significativas en el ámbito de la defensa del usuario de servicios financieros. 


\section{$\mathrm{XVII}$. Algunos comentarios finales}

24. Aunque la necesidad de proteger al consumidor de servicios financieros ha adquirido una relevancia dramática como consecuencia de la crisis financiera, la pasividad política de los 3 primeros años de crisis ha provocado un cierto escepticismo.

Ello es más preocupante aún si tenemos en cuenta que las medidas adoptadas no son en realidad medidas contra la crisis (deuda acumulada, caída del crédito, crédito vivienda), sino «para evitar que vuelva a suceder».

Es urgente una reflexión de fondo sobre cómo actuar con la sobrefinanciación acumulada de las familias y las empresas de una forma lo menos traumática posible pero asegurando una reducción progresiva del riesgo «sistémico» de la misma.

Tanto en las medidas regulatorias a adoptar como en la gestión de los recursos, es necesario dar prioridad al mantenimiento de nuestra estructura social y productiva frente al mantenimiento de las «cifras de balance» de determinadas entidades. 